\title{
PERANCANGAN PEMBANGKIT LISTRIK TENAGA MIKRO HIDRO (PLTMH) DI DESA MAKATI GUNUNG SALAK KABUPATEN BOGOR JAWA BARAT
}

\author{
Ody Septian Pratama ${ }^{1, a)}$, Agus Sukandi ${ }^{2, b)}$, Putu M. Santika ${ }^{3, c)}$ \\ ${ }^{1,2,3)}$ Program Studi Teknik Mesin ITI , \\ Jl. Raya Puspiptek Serpong, Tangerang Selatan-Banten, Indonesia, 15320 \\ a)odyseptianpratama@yahoo.com, ${ }^{\text {b) }}$ agus.sukandi@iti.ac.id ${ }^{\mathrm{c})}$ putu.m.santika@iti.ac.id
}

\begin{abstract}
Abstrak
Di zaman era globalisasi, perkembangan dan kemajuan teknologi sangat pesat yang begitu membutuhkan sumber energi atau tenaga untuk menggerakkan kemajuan tersebut. Dengan kemajuan teknologi yang ada saat ini dan juga adanya potensi pembangkit listrik di daerah terpencil terutama dari potensi air yang begitu melimpah maka perlu dikembangkan pembangkit listrik skala kecil yang disebut Pembangkit Listrik Tenaga Mikro Hidro (PLTMH) yang diharapkan mampu mensuplai energi listrik ke rumah warga dan dengan itu dijadikan sebagai kampung yang mandiri dengan pembangkit listriknya sendiri. Studi ini dilatar belakangi oleh kondisi daerah desa Makati yang belum semuanya terjangkau jaringan listrik, merupakan alasan mendasar untuk memberdayakan potensi air aliran sungai Gunung Salak menjadi sumber Pembangkit Listrik Tenaga Mikrohidro (PLTMH). Di desa Makati, Kecamatan Tenjolaya, Kabupaten Bogor, Jawa Barat. Hasil dari pengukuran debit air dan tinggi jatuh air tersebut, dipergunakan untuk menentukan desain PLTMH, yang meliputi dimensi pipa pesat, jenis turbin air (crossflow) dan dimensi turbin air tipe crossflow. Hasil perhitungan menunjukkan bahwa potensi daya yang dapat dibangkitkan sebesar $100 \mathrm{~kW}$ dengan debit aliran sebesar $3,305 \mathrm{~m}^{3} / \mathrm{s}$ dan tinggi terjunan $10 \mathrm{~m}$. Dari debit air dan tinggi terjunan air tersebut didapatkan desain pipa pesat dengan total panjang $17 \mathrm{~m}$ dan berdiameter $54 \mathrm{~cm}$ serta dimensi turbin yang berdiameter $50 \mathrm{~cm}$ dengan lebar 68,6 cm.
\end{abstract}

Kata kunci: debit aliran, diameter turbin, energi listrik, pembangkit listrik tenaga mikro hidro (PLTMH), turbin air tipe crossflow

\begin{abstract}
In an age of globalization, development and technological progress is very rapid so requires an energy source or energy to drive this progress. With the technological advances that exist today and also their potential for power generation in remote areas, especially from potential water is so abundant it is necessary to develop small scale power plants called Power Micro Hydro Power (MHP), which is expected to supply electrical energy to homes and with that serve as an independent village with its own electric generator. The study was motivated by local conditions Makati village that not all affordable electricity network, was the fundamental reason for the empowering potential of water streams of Mount Salak be a source of micro hydro power plant (MHP). In the village of Makati, District Tenjolaya, Bogor, West Java. The results of measurements of water discharge and the high water fall, is used to determine the design of MHP, which includes rapid pipe dimensions, types of water turbines (crossflow) and dimensions crossflow turbine-type water. The calculations show that the potential power that can be generated by a $100 \mathrm{~kW}$ with a flow rate of $3,305 \mathrm{m3} / \mathrm{s}$ and $10 \mathrm{~m}$ high waterfall. From high waterfall water discharge and water is obtained rapidly design pipe with a total length of $17 \mathrm{~m}$ and a diameter of $54 \mathrm{~cm}$ and dimensions of $50 \mathrm{~cm}$ diameter turbine with a width of $68.6 \mathrm{~cm}$.
\end{abstract}

Keywords: crossflow type water turbine, electrical energy, micro-hydro power plant (MHP), turbine diameter

\section{PENDAHULUAN}

Dalam usaha meningkatkan mutu kehidupan dan pertumbuhan ekonomi pedesaan, energi listrik memiliki peranan yang sangat penting. Ketersediaan energi listrik di pedesaan sebagai salah satu bentuk energi yang siap pakai, selain untuk penerangan tentu saja akan mendorong peningkatan sarana pendidikan, kesehatan dan keamanan lingkungan serta dapat meningkatkan penyediaan lapangan kerja baru.
Salah satu daerah di Provinsi Jawa Barat yang berpotensi untuk dijadikan sumber energi pembangkit listrik tenaga air skala mikro adalah aliran sungai dari Gunung Salak yang terletak di Desa Makati, Kecamatan Tenjolaya, Kabupaten Bogor.

PLTMH (Pembangkit Listrik Tenaga Mikro Hidro), mulai dibangun pada tahun 2008 di Desa Makati, Kecamatan Tenjolaya, Kabupaten Bogor, Jawa Barat. Pada mulanya masyarakat menggunakan mesin diesel 
sebagai penggerak dynamo listrik, mengingat potensi air sungai yang melimpah pemerintah dan warga sekitar akhirnya membangun PLTMH sebagai pengganti mesin diesel. PLTMH yang sekarang digunakan mengalami kendala yang sangat buruk, daya listriknya kurang, tidak aman, mudah rusak, aliran air tidak konstan.

Beberapa upaya yang telah dilakukan adalah memodifikasi instalasi PLTMH mulai perbaikan bendungan, konstruksi kincir air menggunakan plat baja, tetapi masih banyak masalah karena berat dan tidak keseimbangan menyebabkan bantalan poros mudah rusak. Selain dari itu putaran turbin air sangat rendah, membutuhkan sistem transmisi daya yang komplek, dan hasilnya tidak memuaskan, frekuensi listrik tidak stabil, dan merusak peralatan elektronik rumah tangga. Sementara beban listrik tiap tahunnya terus bertambah.

Tujuan dari penelitian ini adalah untuk melakukan studi kelayakan pemanfaatan sumber air aliran sungai Gunung Salak dalam perancangan Pembangkit Listrik Tenaga Mikrohidro (PLTMH) yang bisa memenuhi kebutuhan listrik pada masyarakat Desa Makati dengan menghitung debit air, daya yang bisa dihasilkan dan membuat desain dasar Pembangkit Listrik Tenaga Mikrohidro (PLTMH) dengan mengacu pada sistem sejenis yang telah terpasang didaerah lain.

\section{A. Metode Penulisan}

Dalam penelitian ini menggunakan langkah-langkah sebagai berikut:

1. Mengumpulkan referensi yang berhubungan dengan turbin air

2. Melakukan observasi secara langsung

3. Mengukur dan mendata hasil dari data yang diperlukan

\section{B. Pembatasan Masalah}

Pada penelitian ini hanya pada perancangan dan analisa kerja dari suatu PLTMH berdasarkan studi kelayakan.

Pada penelitian ini pembahasan akan dibatasi pada:

1. Studi kelayakan

2. Perancangan dan analisa perhitungan

\section{LANDASAN TEORI}

A. Pembangkit Listrik Tenaga Mikrohidro (PLTMH)

Pembangkit Listrik Tenaga Mikrohidro (PLTMH) adalah pembangkit listrik yang menggunakan tenaga air sebagai media utama untuk penggerak turbin. Tenaga air dengan skala daya yang dapat dibangkitkan $5 \mathrm{~kW}-50$ kW. Pada PLTMH proses perubahan energi kinetik berupa (kecepatan dan tekanan air), yang digunakan untuk menggerakkan turbin air dan generator listrik hingga menghasilkan energi listrik.

\section{B. Prinsip Kerja Sistem PLTMH}

Secara teknis mikrohidro mempunyai tiga komponen utama yaitu air sumber energi, turbin dan generator. Air yang mengalir dengan kapasitas tertentu disalurkan dengan ketinggian tertentu melalui pipa pesat menuju rumah instalasi (power house). Di rumah instalasi, air tersebut akan menumbuk turbin sehingga akan menghasilkan energi mekanik berupa berputarnya poros turbin. Putaran poros turbin ini akan memutar generator sehingga dihasilkan energi listrik.

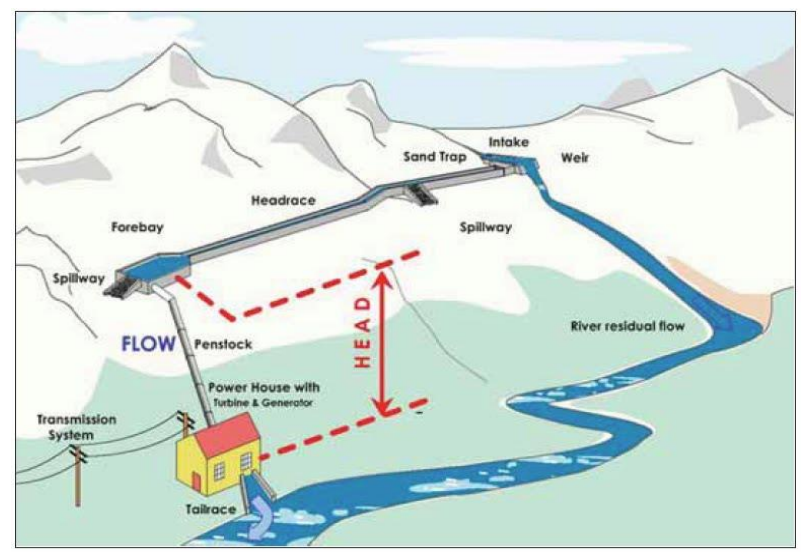

Gambar 1. Skema PLTMH

\section{Penentuan Tinggi Jatuh Efektif}

Untuk menentukan tinggi jatuh yang efektif di dapat berbagai cara untuk mendapatkan, yaitu dengan jenis saluran air dan jenis waduk atau waduk pengantar [1].

\section{Penentuan Debit Turbin}

Untuk menentukan debit turbin diperoleh dengan mengetahui debit maksimum dan jumlah air pasti.

\section{E. Debit Andalan}

Debit minimum sungai dianalisis atas dasar debit hujan sungai. Dalam perencanaan Pembangkit Listrik Tenaga Mikrohidro ini, dikarenakan minimalnya data maka metode perhitungan debit andalan mengunakan metode simulasi perimbangan air dari Dr. F.J.Mock. Dengan data masukan dari curah hujan di Daerah Aliran Sungai, evapotranspirasi, vegetasi dan karakteristik geologi daerah aliran.

Metode ini menganggap bahwa air hujan yang jatuh pada daerah aliran sebagian akan menjadi limpasan langsung dan sebagian akan masuk tanah sebagai air infiltration, kemudian jika kapasitas menampung lengas tanah sudah terlampaui, maka air akan mengalir ke bawah akibat gaya gravitasi [2].

\section{F. Metode Meteorological Water Balance}

Metode ini ditemukan oleh Dr.F.J. Mock pada tahun 1973 dimana metode ini didasarkan atas fenomena alam dibeberapa tempat di Indonesia. Dengan metode ini, besarnya aliran dari data curah hujan, karakteristik hidrologi daerah pengaliran dan evapotranspirasi dapat dihitung. Pada dasarnya metode ini adalah hujan yang jatuh pada catcment area sebagian akan hilang sebagai evapotranspirasi, sebagian akan langsung menjadi aliran permukaan (direct run off) dan sebagian lagi akan masuk kedalam tanah (infiltration), dimana infiltration pertamatama akan menjenuhkan top soil, kemudian menjadi perkolasi membentuk air bawah tanah (ground water) yang nantinya akan keluar ke sungai sebagai aliran dasar (base flow). Adapun ketentuan dari metode ini adalah sebagai berikut.

1. Data meteorologi

Data meterologi yang digunakan mencakup: 
a. Data presipitasi dalam hal ini adalah curah hujan bulanan dan data curah hujan harian.

b. Data klimatologi berupa data kecepatan angin, kelembaban udara, temperatur udara dan penyinaran matahari untuk menentukan evapotranspirasi potensial (Ep) yang dihitung berdasarkan metode "Penman Modifikasi"

2. Evapotranspirasi Aktual (Ea)

Evapotranspirasi aktual adalah evapotranspirasi yang terjadi pada kondisi air yang tersedia terbatas. Evapotranspirasi aktual dipengaruhi oleh proporsi permukaan luar yang tidak tertutupi tumbuhan hijau (exposed surface) pada musim kemarau. Besarnya exposed surface $(\mathrm{m})$ untuk tiap daerah berbeda-beda. Dr. F.J. Mock mengklasifikasikan menjadi tiga daerah dengan masing-masing nilai exposed surface sebagai berikut.

Tabel 1. Exposed Surface dalam metode Mock

\begin{tabular}{|l|l|l|}
\hline \multicolumn{1}{|c|}{ No. } & $\begin{array}{c}\text { Exposed } \\
\text { Surface }(\mathbf{m})\end{array}$ & \multicolumn{1}{c|}{ Daerah } \\
\hline 1 & $0 \%$ & Hutan primer, sekunder \\
\hline 2 & $10 \%-40 \%$ & Daerah tererosi \\
\hline 3 & $30 \%-50 \%$ & Daerah ladang pertanian \\
\hline
\end{tabular}

\section{G. Komponen Pokok Mikrohidro}

Merupakan komponen yang paling dominan di dalam pembangunan PLTMH. Skema dari sistem PLTMH ditunjukkan pada gambar 2. [3].

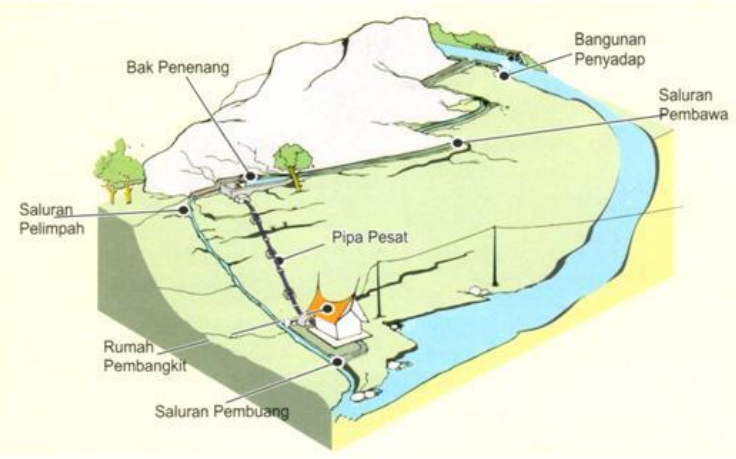

Gambar 2. Skema sistim PLTMH

Dari gambar diatas, suatu rangkaian sistem PLTMH memiliki bagian-bagian utama sebagai berikut [4].

1. Dam/Bendungan pengalih dan intake (Diversion weir and intake)

Bendungan berfungsi untuk menaikkan/mengontrol tinggi air dalam sungai secara signifikan sehingga memiliki jumlah air yang cukup untuk dialihkan ke dalam intake pembangkit mikrohidro di bagian sisi sungai ke dalam sebuah bak pengendap (settling basin). Sebuah bendungan dilengkapi dengan pintu air untuk membuang kotoran/lumpur yang mengendap. Perlengkapan lainnya adalah penjebak/saringan sampah. PLTMH umumnya merupakan pembangkit tipe run off river sehingga bangunan bendung dan intake dibangun derdekatan. Dengan pertimbangan dasar stabilitas sungai dan aman terhadap banjir, dapat dipilih lokasi untuk bendung (weir) dan intake.

2. Bak pengendap (Settling basin)

Berikut fungsi dari bak pengendap yaitu :

a. Penyalur yang menghubungkan intake dengan bak pengendap sehingga panjangnya harus di batasi.

b. Mengatur aliran air dari saluran penyalur sehingga harus mencegah terjadinya kolam pusaran dan aliran turbulen serta mengurangi kecepatan aliran masuk ke bak pengendap sehingga perlu bagian melebar.

c. Sebagai bak pengendap adalah untuk mengendapkan sedimen dimana untuk detil desainnya perlu dihitung dengan formulasi hubungan panjang bak, kedalaman bak, antara kecepatan pengendap dan kecepatan aliran.

3. Saluran pembawa (Headrace)

Saluran pembawa mengikuti kontur permukaan bukit berfungsi untuk menjaga elevasi dari air yang disalurkan.

4. Bak penenang (Headtank)

Fungsi dari bak penenang adalah sebagai penyaring terkhir seperti bak pengendap untuk menyaring benda-benda yang masih tersisa dalam aliran air, dan merupakan tempat permulaan pipa pesat (penstock) yang mengendalikan aliran menjadi minimum sebagai antisipasi aliran yang cepat pada turbin tanpa menurunkan elevasi muka air yang berlebihan dan menyebabkan arus balik pada saluran.

5. Pipa pesat (Penstock)

Pipa pesat (penstock) dihubungkan pada sebuah elevasi yang lebih rendah ke sebuah turbin air. Kondisi topografi dan pemilihan skema PLTMH mempengaruhi tipe pipa pesat. Umumnya sebagian saluran ini harus didesain/dirancang secara benar sesuai kemiringan head sistem PLTMH.

6. Rumah pembangkit (Power house)

Sesuai posisinya, rumah pembangkit ini dapat diklasifikasikan kedalam tipe di atas tanah, semi di bawah tanah. Sebagian besar rumah pembangkit PLTMH adalah di atas tanah. Terkait desain rumah pembangkit, perlu pertimbangan sebagai berikut:

a. Lantai rumah pembangkit dimana peralatan PLTMH ditempatkan, perlu memperhatikan kenyamanan selama operasi, mengelola, melakukan perawatan dimana terjadi pekerjaan 
pembongkaran dan pemasangan peralatan.

b. Memiliki cukup cahaya masuk untuk penerangan di siang hari dan adanya ventilasi udara.

c. Kenyamanan jika operator berada di dalamnya seperti untuk melakukan pengendalian ataupun pencatatan secara manual.

\section{H. Jenis Turbin Air}

Turbin air berperan untuk mengubah energi air (energi potensial, tekanan dan energi kinetik) menjadi energi mekanik dalam bentuk putaran poros. Putaran poros turbin ini akan diubah oleh generator menjadi tenaga listrik. Berdasarkan prinsip kerjanya, turbin air dibagi menjadi dua kelompok [5].

1. Turbin impuls (turbin pelton, crossflow dan turgo)

Untuk jenis turbin ini, tekanan pada setiap sisi sudu gerak runner nya pada bagian turbin yang berputar sama. Disini beda tinggi diubah menjadi kecepatan karena perbedaan tinggi. Yang khas dari jenis ini adalah turbin pelton, dengan pasangan ember-ember (buckets) pada keliling rotor yang bekerja karena pancaran air (jet discharge) dari mulutnya (nozzle).

2. Turbin reaksi (turbin francis, kaplan propeller)

Untuk jenis turbin ini, digunakan untuk berbagai keperluan (wide range) dengan tinggi terjun menengah (medium head). Turbin jenis ini dibuat sedemikian sehingga rotor bekerja karena aliran air dengan tinggi terjun karena tekanan. Yang termasuk jenis ini adalah turbin francis, turbin aliran diagonal (diagonal flow), dan turbin baling-baling (propeller turbine). Turbin francis adalah turbin dimana air mengalir ke rotor dengan arah radial dan keluar dengan arah aksial. Perubahan arah terjadi dengan melawan arah rotor. Turbin aliran diagonal adalah turbin dimana air melewati rotor dengan arah diagonal menuju ke poros. Turbin baling-baling adalah turbin dimana air melewati rotor dengan arah aksial. Turbin reaksi dapat dipakai sebagai pompa dengan membalik arah putaran rotor dinamakan turbin pompa balik (reversible pump turbine). Turbin jenis ini terbagi lagi atas jenis francis, aliran diagonal, dan jenis baling-baling, sesuai dengan konstruksi rotornya.

\section{Persamaan Bernoulli}

Prinsip Bernoulli adalah sebuah istilah di dalam mekanika fluida yang menyatakan bahwa pada suatu aliran fluida, peningkatan pada kecepatan fluida akan menimbulkan penurunan tekanan pada aliran tersebut. Prinsip ini sebenarnya merupakan penyederhanaan dari Persamaan Bernoulli yang menyatakan bahwa jumlah energi pada suatu titik di dalam suatu aliran tertutup sama besarnya dengan jumlah energi di titik lain pada jalur aliran yang sama [6].

$$
\frac{P_{1}}{\rho \cdot g}=\frac{v_{1}^{2}}{2 \cdot g}+g \cdot h_{1}=\frac{P_{2}}{\rho \cdot g}=\frac{v_{2}}{2 \cdot g}+g \cdot h_{2}
$$

(1)

$$
\frac{v_{1}^{2}}{2 \cdot g}+g \cdot h_{1}=\frac{v_{2}}{2 \cdot g}
$$

dimana:

$$
\begin{aligned}
& =\text { tekanan }\left(\mathrm{N} / \mathrm{m}^{2}\right) \\
& =\operatorname{kecepatan} \text { aliran fluida }(\mathrm{m} / \mathrm{s}) \\
& =\text { perceatan gravitasi }\left(\mathrm{m} / \mathrm{s}^{2}\right) \\
& =\text { massa jenis fluida }\left(\mathrm{kg} / \mathrm{m}^{2}\right) \\
& =\text { ketinggian pipa dari tanah }(\mathrm{m})
\end{aligned}
$$

\section{J. Debit Aliran}

Debit aliran adalah jumlah air yang mengalir dalam satuan volume per waktu. Debit adalah satuan besaran air yang keluar dari Daerah Aliran Sungai (DAS). Satuan debit yang digunakan adalah meter kubir per detik $\left(\mathrm{m}^{3} / \mathrm{s}\right)$. Debit aliran adalah laju aliran air (dalam bentuk volume air) yang melewati suatu penampang melintang sungai per satuan waktu.

$$
\mathrm{Q}=A \cdot v
$$

dimana:

$$
\begin{array}{ll}
\mathrm{Q} & =\text { debit aliran }\left(\mathrm{m}^{3} / \mathrm{s}\right) \\
A & =\text { luas penampang }\left(\mathrm{m}^{2}\right) \\
v & =\text { kecepatan aliran fluida }(\mathrm{m} / \mathrm{s})
\end{array}
$$

\section{K. Daya Listrik Yang Dibangkitkan}

Daya Listrik atau dalam bahasa Inggris disebut dengan Electrical Power adalah jumlah energi yang diserap atau dihasilkan dalam sebuah sirkuit/rangkaian. Sumber energi seperti tegangan listrik akan menghasilkan daya listrik sedangkan beban yang terhubung dengannya akan menyerap daya listrik tersebut. Dengan kata lain, daya listrik adalah tingkat konsumsi energi dalam sebuah sirkuit atau rangkaian listrik.

dimana:

$$
P=g \cdot \rho \cdot Q \cdot H . \mathrm{H}
$$

$$
\begin{array}{ll}
\mathrm{P} & =\text { daya yang dibangkitkan }(\mathrm{kW}) \\
g & =\text { perceatan gravitasi }\left(\mathrm{m} / \mathrm{s}^{2}\right) \\
\rho & =\text { massa jenis fluida }\left(\mathrm{kg} / \mathrm{m}^{2}\right) \\
\mathrm{Q} & =\text { debit aliran }\left(\mathrm{m}^{3} / \mathrm{s}\right) \\
H & =\text { tinggi terjunan }(\mathrm{m}) \\
\eta & =\text { efesiensi }
\end{array}
$$

\section{Kapasitas Aliran Air Pipa Pesat}

Besarnya kapasitas aliran air yang mengalir ke turbin melalui pipa pesat (penstock) dapat diperoleh dengan menggunakan persamaan berikut.

$$
\mathrm{Q}=\frac{75 \cdot P}{\rho \cdot \eta \cdot \AA}
$$

dimana:

$$
\begin{aligned}
& \text { Q = besarnya kapasitas aliran air masuk } \\
& \text { ke pipa pesat }\left(\mathrm{m}^{3} / \mathrm{s}\right) \\
& \mathrm{P} \quad=\text { daya yang dibangkitkan }(\mathrm{kW}) \\
& \rho \quad=\text { massa jenis fluida }\left(\mathrm{kg} / \mathrm{m}^{2}\right)
\end{aligned}
$$




$$
\begin{array}{ll}
\eta & =\text { efesiensi } \\
h & =\text { ketinggian pipa dari tanah }(\mathrm{m})
\end{array}
$$

\section{J. Perancangan Instalasi Pipa Pesat}

Pipa pesat (penstock) adalah saluran yang digunakan untuk mengalirkan air dari sumber air (head race) ke rumah turbin. Sehingga panjang pipa pesat (penstock) keseluruhan adalah.

dimana:

$$
L=L_{1}+L_{2}+L_{3}
$$

$$
\begin{array}{ll}
L & =\text { panjang keseluruhan pipa pesat }(\mathrm{m}) \\
L_{1} & =\text { panjang pipa dari reservoir }(\mathrm{m}) \\
L_{2} & =\text { panjang pipa penghubung }(\mathrm{m}) \\
L_{3} & \quad \text { panjang pipa ke pusat turbin }(\mathrm{m})
\end{array}
$$

\section{K. Diameter Pipa Pesat}

Diameter pipa pesat (penstock) dapa dihitung dengan menggunakan persamaan sebagai berikut.

$$
\mathrm{Q}=\frac{0,3968}{n} \times \frac{\pi}{4} x D^{\mathrm{g} / \mathrm{a}} x \mathrm{~s}^{1 / 2}
$$

dimana:

$$
\begin{array}{ll}
\mathrm{Q} \quad= & \text { besarnya kapasitas aliran air masuk } \\
& \text { ke pipa pesat }\left(\mathrm{m}^{3} / \mathrm{s}\right) \\
n & =
\end{array}
$$

\section{Kecepatan Aliran Air Di Dalam Pipa}

Besarnya kecepatan aliran air yang mengalir ke turbin melalui pipa pesat (penstock) dapat diperoleh dengan menggunakan persamaan berikut [7].

$$
v=\frac{Q}{\frac{\pi}{4} \times D i^{2}}
$$

dimana:

$$
\begin{aligned}
v & =\text { kecepatan aliran fluida }(\mathrm{m} / \mathrm{s}) \\
\mathrm{Q} & = \\
& \text { besarnya kapasitas aliran air masuk } \\
& \text { ke pipa pesat }\left(\mathrm{m}^{3} / \mathrm{s}\right) \\
D i & =
\end{aligned}
$$

\section{Desain Turbin Crossflow}

Terdapat beberapa poin untuk mendesain turbin crossflow yaitu meliputi torsi, bahan turbin, diameter poros, lebar dan diameter runner, putaran turbin, tebal pancaran, jarak antara sudu, jumlah sudu, lebar keliling radial,kelengkungan sudu, jarak pancaran dari pusat poros, dan putaran spesifik turbin.

\section{Torsi}

Jika torsi disebut juga sebagai momen puntir atau momen rencana adalah $T$ (kg.mm) [8], maka:

$$
T=9,74.10^{5} . P / n
$$

dimana:

$T=$ torsi / momen punter $(\mathrm{kg} \cdot \mathrm{mm})$
$P \quad=$ daya yang dibangkitkan $(\mathrm{kW})$

$n \quad$ = putaran pada daya yang dibangkitkan (rpm)

2. Bahan Turbin

Bahan turbin memakai baja ST70, yang memiliki makna kekuatan tarik atau tegangan tarik sebesar $70 \mathrm{~kg} / \mathrm{mm}^{2}$ atau $700 \mathrm{~N} / \mathrm{mm}^{2}$. Maka tegangan geser $\tau_{\mathrm{a}}$ adalah sebagai berikut.

$$
\tau_{a}=\frac{\tau_{b}}{S f_{1} x S f_{2}}
$$

dimana:

$$
\begin{aligned}
& \tau_{\mathrm{a}} \quad=\text { tegangan geser }\left(\mathrm{kg} \cdot \mathrm{mm}^{2}\right) \\
& \tau_{\mathrm{b}} \quad=\text { tegangan tarik }\left(\mathrm{kg} \cdot \mathrm{mm}^{2}\right) \\
& S f_{1} \quad=\text { faktor pengaruh masa, dan baja } \\
& \text { paduan }(5,6 \text { untuk bahan SF dan } \\
& \text { 6,0 untuk bahan S-C) } \\
& S f_{2} \quad=\text { faktor pengaruh kekasaran } \\
& (1,3 \text { sampai } 3,0)
\end{aligned}
$$

3. Diameter Poros

Dari persamaan (8) dan (9) didapat persamaan untuk menghitung diameter poros $d_{\text {poros }}(\mathrm{mm})$.

$$
d_{\text {poros }}=\left[\frac{5,1}{\tau_{a}} \times K_{\mathrm{t}} \times C_{b} \times T\right]^{\frac{1}{a}}
$$

Dimana:

$$
\begin{aligned}
\tau_{\mathrm{a}} \quad= & \text { tegangan geser }\left(\mathrm{kg} \cdot \mathrm{mm}^{2}\right) \\
K t \quad= & \text { faktor koreksi keadaan momen punter } \\
& (1,0 \text { jika beban dikenakan secara } \\
& \text { halus, } 1,0-1,5 \text { jika terjadi kejutan } \\
& \text { atau tumbukan, dan } 1,5-3,0 \text { jika } \\
& \text { beban dikenakan dengan kejutan atau } \\
& \text { tumbukan besar. } \\
= & \text { fakor beban lentur }(1,2 \text { sampai } 2,3) \\
& =\text { torsi / momen puntir }(\mathrm{kg} . \mathrm{mm})
\end{aligned}
$$

4. Lebar dan Diameter Runner

Dengan konstanta tetapan $\mathrm{C}=0,98$ dan $\mathrm{k}=0,087$ [9].

$$
L=\frac{144 \cdot Q}{C \cdot k \cdot(2 \cdot g)^{1 / 2}}
$$

Sehingga lebar diameter:

$$
\mathrm{LD}=\mathrm{L} \cdot \mathrm{Q} \cdot \mathrm{h}^{1 / 2}
$$

Untuk mencari lebar turbin:

$$
L=\frac{L D}{D}
$$

dengan $\mathrm{L}$ dan $\mathrm{D}$ dalam $\mathrm{cm}$ 
dimana:

$L \quad=$ lebar runner $(\mathrm{cm})$

$Q \quad=$ kapasitas aliran pipa pesat $\left(\mathrm{m}^{3} / \mathrm{s}\right)$

$g \quad=$ perceatan gravitasi $\left(\mathrm{m} / \mathrm{s}^{2}\right)$

$h \quad=$ ketinggian pipa dari tanah (m)

5. Putaran Turbin

Berikut adalah persamaan untuk mendapatkan putaran turbin [10].

$$
n=862 / D \cdot(10)^{1 / 2}
$$

dimana:

$$
\begin{array}{ll}
n & =\text { putaran turbin }(\mathrm{rpm}) \\
D & =\text { diameter runner }
\end{array}
$$

6. Tebal Pancaran

Berikut adalah persamaan untuk menghitung tebal pancaran.

$$
\mathrm{A}=\frac{Q}{v}
$$

dimana:

$\mathrm{Q} \quad=$ kapasitas aliran pada pipa pesat

$\mathrm{v} \quad=$ kecepatan aliran air pada pipa pesat

Sehingga tebal pancaran $\mathrm{S}_{0}$,

$$
S_{0}=\frac{A}{L}
$$

7. Jarak Antar Sudu

Berdasarkan gambar 3, diperoleh persamaan sebagai berikut.

$$
S_{1}=k \cdot D
$$

Sehingga jarak antara sudu menjadi,

$$
\mathrm{t}=S_{1} / \sin \beta 30
$$

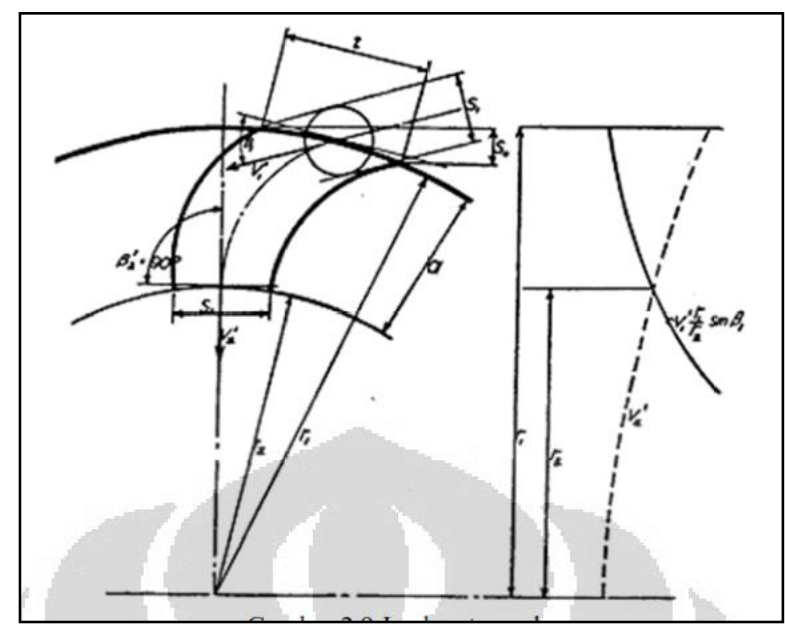

Gambar 3. Jarak antar sudu

\section{Jumlah Sudu}

Jumlah sudu dirumuskan sebagai beikut.

$$
N=\pi \cdot D_{1} / t
$$

9. Lebar Keliling Radial

Lebar keliling radial dirumuskan sebagai berikut.

$$
\alpha=0,17 \times D_{1}
$$

10. Kelengkungan Sudu

Kelengkungan sudu dirumuskan sebagai berikut.

$$
\rho=0,326 \cdot r_{1}
$$

11. Jarak Pancaran Dari Pusat Poros

Jarak pancaran dari pusat poros dirumuskan sebagai berikut.

$$
y_{1}=(0,1986-0,945 . k) D_{1}
$$

12. Putaran Spesifik Turbin

Putaran spesifik turbin dirumuskan sebagai berikut [11].

$$
n_{g}=\frac{n \sqrt{P}}{h^{5 / 4}}
$$

dimana:

$$
\begin{array}{ll}
p & =\text { daya turbin }(\mathrm{kW}) \\
h & =\text { tinggi air jatuh }(\mathrm{m}) \\
n & =\text { putaran turbin }(\mathrm{rpm})
\end{array}
$$

\section{METODE PENELITIAN}

A. Diagram Alir Penelitian

Gambar 4 menunjukkan diagram alir pelaksanaan penelitian.

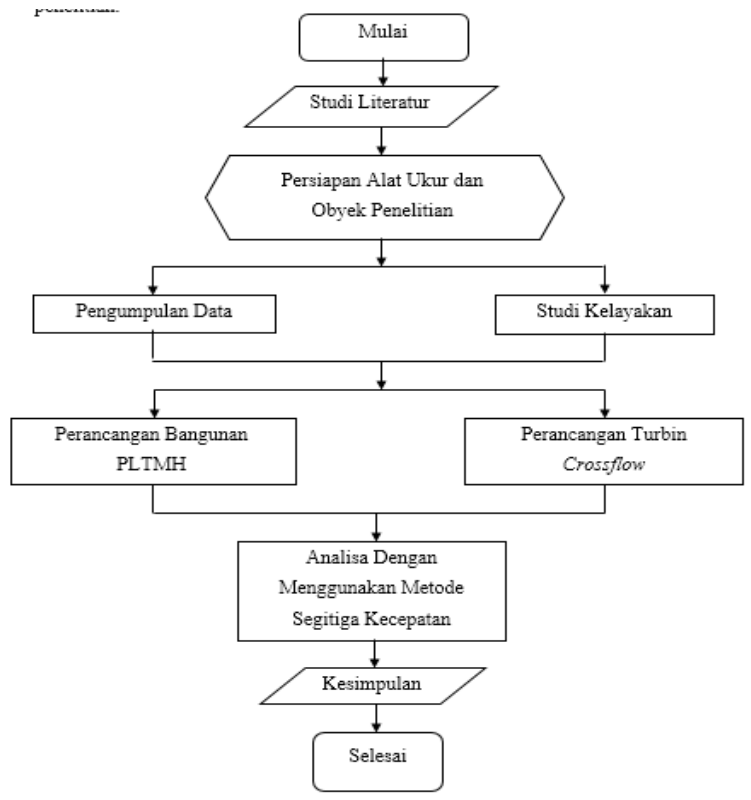

Gambar 4. Diagram alir

B. Lokasi Penelitian 
Lokasi yang menjadi penelitian ini adalah Sungai dari Gunung Salak yang merupakan sungai dengan potensi airnya yang sangat melimpah dan dekat dari pemukiman warga. Secara administratif terletak di Desa Makati, Kecamatan Tenjolaya, Kabupaten Bogor. Jarak dari kota Bogor ke lokasi penelitian sekitar $50 \mathrm{~km}$.

\section{Langkah Penelitian}

1. Pengumpulan data

Mengumpulkan data-data dari berbagai referensi yang terkait dengan penelitian yang akan dilakukan, diantaranya:

a. Mengukur tinggi muka air, kecepatan dan luas penampang sungai.

b. Merencanakan Site Plan.

c. Menentukan letak / posisi intake saluran pengambil air pada sungai.

d. Menentukan bak pengendap.

e. Menentukan dimensi salurah pengaruh dan bak penenang.

f. Menentukan bahan dan dimensi pipa yang akan digunakan.

g. Mengukur tinggi terjunan dan jarak lintasan pipa dari bak penenang sampai ke power house.

\section{Persamaan}

Menggunakan persamaan daya dan metode geometrik yang akan dipakai dalam perhitungan.

3. Pembahasan

Data yang telah diolah kemudian dibahas untuk mendapatkan hasil dari penulisan penelitian.

4. Perhitungan

Menghitung daya yang dihasilkan oleh PLTMH.

\section{Pengambilan Data}

1. Survei pendahuluan

Survei pendahuluan dimaksudkan untuk mengetahui sampai sejauh mana survei dapat diterapkan dan untuk mengetahui gambaran awal kondisi di lapangan.

2. Pengumpulan data

Adapun data yang digunakan dalam penelitian ini adalah data primer dan data sekunder. Data-data yang dikumpulkan antara lain:

a. Data primer berupa:

- Data dimensi sungai.

- Data kondisi sungai, seperti kedalaman sungai, tinggi terjunan (head).

b. Data sekunder:

- Data curah hujan.

- Peta topografi.

\section{E. Studi Kelayakan}

Terdapat beberapa poin kegiatan untuk melakukan studi kelayakan yaitu menentukan gambaran umum lokasi, mengumpulkan peta topografi, kondisi hidrologis, kualitas air dan curah hujan.

\section{F. Data Beban Konsumen}

Beban konsumen di desa Makati dibedakan menjadi 2 golongan beban pada rumah yang memiliki fasilitas seperti televisi, kulkas, mesin cuci, dan lain lain. Sedangkan rumah yang tidak memiliki fasilitas tersebut hanya menggunakan lampu untuk penerangan rumah. Rumah yang memiliki fasilitas diasumsikan memakai beban 900 Watt sebanyak 20 rumah, sedangkan yang tidak memiliki fasilitas diasumsikan 450 Watt sebanyak 10 rumah. Termasuk 2 unit bangunan fasilitas umum, dan akan bertambah seiring bertambahnya jumlah penduduk. Mengacu pada standar PLN (perusahaan listrik negara) beban konsumen mulai dari 450 Watt, 900 Watt, 1300 Wattt dan 2200 Watt. Diperoleh perkiraan daya yang dibutuhkan.

$$
\mathrm{P}_{\mathrm{T}}=(20 \times 900)+(2 \times 900)+(10 \times 450)
$$

$=23,44 \mathrm{~kW}$ (perkiraan pada saat beban maksimum)

\section{G. Transmisi dan Distribusi}

Di mana terdapat beberapa poin untuk menentukan transmisi dan distribusi dari perancangan PLTMH yaitu meliputi pemilihan jalur transmisi, penerapan trafo distribusi, dan sambungan rumah.

\section{HASIL DAN PEMBAHASAN}

\section{A. Hasil Pengamatan}

Dari hasil pengamatan dengan metode penelitian yang telah dilakukan di aliran Sungai Gunung Salak, didapat sketsa penampang sungai yang ditunjukan pada gambar 5, kemudian dilakukan pngukuran kecepatan aliran air sungai, kedalaman sungai, dan menghitung debit aliran air sungai.

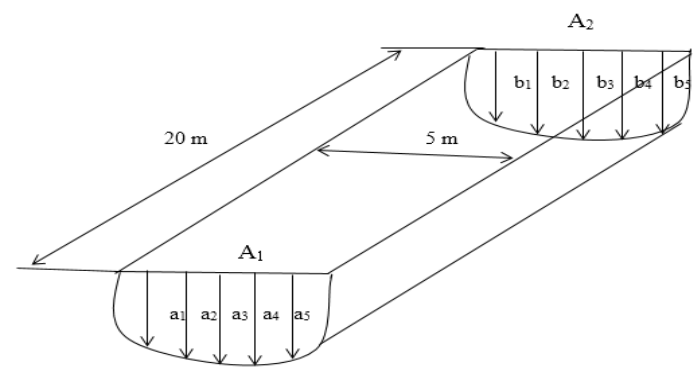

Gambar 5. Sketsa ukuran sungai

B. Hasil Perhitungan Data

Tabel 2. Hasil pengukuran sungai

\begin{tabular}{|c|c|}
\hline No & $A_{1}$ (kedalaman) \\
\hline $\mathrm{a}_{1}$ & 1,73 \\
\hline $\mathrm{a}_{2}$ & 1,7 \\
\hline $\mathrm{a}_{3}$ & 1,8 \\
\hline $\mathrm{a}_{4}$ & 1,8 \\
\hline $\mathrm{a}_{5}$ & 1,5 \\
\hline
\end{tabular}

\begin{tabular}{|c|c|}
\hline No & $A_{2}$ (kedalaman) \\
\hline$b_{1}$ & 0,61 \\
\hline$b_{2}$ & 0,8 \\
\hline$b_{3}$ & 1 \\
\hline$b_{4}$ & 0,7 \\
\hline$b_{5}$ & 0,75 \\
\hline
\end{tabular}


Tabel 3. Data potensi aliran sungai

\begin{tabular}{|c|l|c|c|c|}
\hline No & \multicolumn{1}{|c|}{ Besaran } & Simbol & Nilai & Satuan \\
\hline 1 & Kecepatan aliran air & $v$ & 0,521 & $\mathrm{~m} / \mathrm{s}$ \\
\hline 2 & Head & $H$ & 3 & $\mathrm{~m}$ \\
\hline 3 & Debit aliran & $Q$ & 3,305 & $\mathrm{~m}^{3} / \mathrm{s}$ \\
\hline 4 & Daya hidrolis air & $P$ & 80 & $\mathrm{~kW}$ \\
\hline 5 & Daya turbin (dari & $P t$ & 100 & $\mathrm{~kW}$ \\
\hline 6 & $\begin{array}{l}\text { Kecepatan } \\
\text { pers Bernoulli) }\end{array}$ & 43,87 & $\mathrm{~m} / \mathrm{s}$ \\
\hline
\end{tabular}

Tabel 4. Data teknis pipa pesat

\begin{tabular}{|c|c|c|c|c|}
\hline No & Besaran & Simbol & Nilai & Satuan \\
\hline 1 & $\begin{array}{l}\text { Ketinggian pipa } \\
\text { tinggi air jatuh }\end{array}$ & $h$ & 10 & $\mathrm{~m}$ \\
\hline 2 & $\begin{array}{l}\text { Kapasitas aliran air } \\
\text { pipa pesat }\end{array}$ & $Q$ & 0,88 & $\mathrm{~m}^{3} / \mathrm{s}$ \\
\hline 3 & $\begin{array}{l}\text { Panjang pipa dari } \\
\text { reservoir atas }\end{array}$ & L1 & 1 & $\mathrm{~m}$ \\
\hline 4 & $\begin{array}{ll}\text { Panjang } & \text { pipa } \\
\text { penghubung }\end{array}$ & $L 2$ & 10 & $\mathrm{~m}$ \\
\hline 5 & $\begin{array}{l}\text { Panjang pipa } \\
\text { kepusat turbin }\end{array}$ & L3 & 2 & $\mathrm{~m}$ \\
\hline 6 & $\begin{array}{l}\text { Panjang pipa pesat } \\
\text { keseluruhan }\end{array}$ & $L$ & 17 & $\mathrm{~m}$ \\
\hline 7 & Diameter pipa pesat & $D$ & 540 & $\mathrm{~mm}$ \\
\hline 8 & $\begin{array}{l}\text { Kecepatan aliran air } \\
\text { didalam pipa }\end{array}$ & $v$ & 6,672 & $\mathrm{~m} / \mathrm{s}$ \\
\hline
\end{tabular}

Tabel 5. Data desain turbin crossflow

\begin{tabular}{|c|l|c|c|c|}
\hline No & \multicolumn{1}{|c|}{ Besaran } & Simbol & Nilai & Satuan \\
\hline 1 & Torsi & $T$ & 779200 & $\mathrm{~kg} \cdot \mathrm{mm}$ \\
\hline 2 & Bahan turbin & - & $\mathrm{ST70}$ & $\begin{array}{c}70 \\
\mathrm{~kg} / \mathrm{mm}^{2}\end{array}$ \\
\hline 3 & Tegangan tarik & $\tau_{b}$ & 70 & $\mathrm{~kg} / \mathrm{mm}^{2}$ \\
\hline 4 & Tegangan geser & $\tau_{a}$ & 58 & $\mathrm{~N} / \mathrm{mm}^{2}$ \\
\hline 5 & Diameter poros & $d_{p o r o s}$ & 140 & $\mathrm{~mm}$ \\
\hline 6 & Diameter runner & $D$ & 500 & $\mathrm{~mm}$ \\
\hline 7 & Lebar runner & $L$ & 690 & $\mathrm{~mm}$ \\
\hline 8 & Putaran turbin & $n$ & 545 & $\mathrm{rpm}$ \\
\hline 9 & Tebal pancaran & $S_{0}$ & 194,11 & $\mathrm{~mm}$ \\
\hline 10 & Jarak antar sudu & $t$ & 87 & $\mathrm{~mm}$ \\
\hline 11 & Jumlah sudu & $N$ & 18 & $\mathrm{Buah}$ \\
\hline 12 & $\begin{array}{l}\text { Lebar keliling } \\
\text { radial }\end{array}$ & $A$ & 85 & $\mathrm{~mm}$ \\
\hline 13 & Kelengkungan sudu & $\rho$ & 81,5 & $\mathrm{~mm}$ \\
\hline 14 & $\begin{array}{l}\text { Jarak pancaran dari } \\
\text { pusat poros }\end{array}$ & $y_{l}$ & 58,2 & $\mathrm{~mm}$ \\
\hline 15 & $\begin{array}{l}\text { Putaran spesifik } \\
\text { turbin }\end{array}$ & $n_{s}$ & 306 & $\mathrm{rpm}$ \\
\hline
\end{tabular}

\section{KESIMPULAN}

1. Potensi air pada aliran sungai Gunung Salak di Desa Makati memungkinkan dibangun
Pembangkit Listrik Tenaga Mikrohidro (PLTMH) dengan konstruksi yang sederhana.

2. Perancangan Pembangkit Listrik Tenaga Mikrohidro sederhana dari segi mekanismenya di daerah Desa Makati tidak menggunakan turbin berkapasitas besar melainkan menggunakan turbin tipe crossflow yang didesain untuk menggerakkan generator dengan kapasitas $100 \mathrm{~kW}$.

3. Dari hasil analisa data didapat debit aliran sungai Gunung Salak sebesar 3,227 $\mathrm{m}^{3} / \mathrm{s}$. Sedangkan debit yang dibutuhkan untuk memutar turbin sebesar $0,88 \mathrm{~m}^{3} / \mathrm{s}$.

4. Berdasarkan persamaan Bernoulli maka didapat hasil kecepatan aliran konstan sebesar 43,87 m/s.

5. Diameter pipa pesat (penstock) didapat sebesar $54 \mathrm{~cm}$, dengan total panjang $17 \mathrm{~m}$ dan kecepatan aliran di dalam pipa sebesar $6,672 \mathrm{~m} / \mathrm{s}$.

6. Putaran turbin sebesar $545 \mathrm{rpm}$ untuk diameter turbin $50 \mathrm{~cm}$, dengan diamater poros $14 \mathrm{~cm}$.

7. Jumlah sudu turbin 18 buah, lebar keliling radial $8,5 \mathrm{~cm}$, dengan kelengkungan sudu sebesar 8,15 $\mathrm{cm}$.

8. Dengan putaran spesifik turbin didapat $306 \mathrm{rpm}$.

\section{REFERENSI}

[1] Arismunandar, A. 1975. Teknik Tenaga Listrik "Pembangkitan Dengan Tenaga Air". Jakarta : Pradnya Paramita

[2] Mock, F.J. 1973. Basic Study Prepared for the FAO / UNDP Land Capability Apprasial Project. Bogor : Tidak Diterbitkan

[3] Nugroho, Daniel. 2011. Komponen Pembangkit Listrik Tenaga Mikrohidro. September 28, 2016. http://www.danielnugroho.com/wpcontent/uploads/Komponen-PLTMH

[4] Pimpii. 2011. Skema Hydro Power. September 28, 2016

https://pimpii.files.wordpress.com/2011/06/

[5] Alif. 2012. Pemanfaatan Energi Air Untuk BTS Remote Area. September 28, 2016. https://aliefworkshop.wordpress.com/tag/turbin/

[6] Victor L. Streeter. 1993. Mekanika Fluida : Edisi ke-8 Jilid 1. Jakarta : Penerbit Erlangga

[7] Sutarno. 1973. Sistim Listrik Mikrohidro Untuk Kelistrikan Desa. Yogyakarta : UGM Yogyakarta

[8] Sularso. 1978. Dasar Perencanaan dan Pemilihan: Elemen Mesin. Jakarta: Pradnya Paramita

[9] Haimerl, L.A., 1960. The Cross Flow Turbine. Jerman Barat

[10] Mockmore, C., \& Merryfield, F. 1949. The Banki Water Turbine "Engineering Experiment Station Oregon State Collage”.Bulletin Series No. 25

[11] Lal, Jagdish. 1975. Hydraulic Machine. New Delhi : Metropolitan Book Co Private Ltd 